Article

\title{
Research on Factors Affecting the Optimal Exploitation of Natural Gas Resources in China
}

\author{
Jianzhong Xiao ${ }^{1,2}$, Xiaolin Wang ${ }^{1, *}$ and Ran Wang ${ }^{2}$ \\ 1 School of Economics and Management, China University of Geosciences, Wuhan 430074, China; \\ xjianzhong@cug.edu.cn \\ 2 Resources and Environment Economic Research Center, China University of Geosciences, Wuhan 430074, \\ China; wangran2cug@163.com \\ * Correspondence: wangxiaolin_cug@163.com; Tel.:+86-27-6788-3201
}

Academic Editor: Bing Wang

Received: 16 January 2016; Accepted: 26 April 2016; Published: 2 May 2016

\begin{abstract}
This paper develops an optimizing model for the long-term exploitation of limited natural gas reserves in China. In addition to describing the life cycle characteristics of natural gas production and introducing the inter-temporal allocation theory, this paper builds the optimal exploitation model of natural gas resources within a gas field in the Ordos Basin as an example to analyze its exploitation scale and how influence factors, such as recovery rate, discount rate and the gas well exhausting cycle, affect the optimal exploration path of this gas field. We determine that an increase in the discount rate stimulates investors to invest more aggressively in natural gas exploitation in the early period due to the lower discounted value, thereby increasing the pace of the exploitation of natural gas and the exhaustion of gas fields. A higher recoverable factor implies more recoverable reserves and greater potential of increasing the output of gas fields. The exhaustion rate of gas wells affects the capability of converting capacity to output. When exhaustion occurs quickly in gas wells, the output will likely increase in the output rising period, and the output will likely decrease at a faster rate in the output reduction period. Price reform affects the economic recoverable reserves of gas fields.
\end{abstract}

Keywords: natural gas resources; optimal exploitation model; recovery rate; discount rate; exhausting rate; gas pricing

\section{Introduction}

In this study, we develop an optimizing model for the long-term exploitation of limited natural gas reserves in China, which is a coal-dominated energy structure economy and suffers from serious pollution problems. Nevertheless, natural gas is currently promoted by Chinese authorities due to its relatively low carbon dioxide emissions. Therefore, the Chinese government confirmed its strong determination to increase domestic supply and to narrow the increasing gap between demand and production [1,2].

A large proportion of natural gas supply activities that include exploration, extraction and transportation of gas in China are currently overseen by the National Oil Company (NOC). In the current liberalized environment, investment from the private sector is encouraged. Upstream activities (exploration and extraction) are in dire need of investment, and because these investments are scarce resources, they need to be spread among various potentially productive basins.

According to Dai et al. [3], conventional gas geological resources in China have increased from $(5.4-7) \times 10^{12} \mathrm{~m}^{3}$ in 1981 to $63 \times 10^{12} \mathrm{~m}^{3}$ in 2010; these data have been assessed by various scholars and divisions over the past thirty years and, thus, are validated. China recorded (39.0-39.2) $\times 10^{12} \mathrm{~m}^{3}$ recoverable conventional gas resources; this is an immense amount for any type of major gas producer and will provide a solid foundation for the sustainable development of China's natural gas industry. 
However, large gas fields in China are mainly distributed in the mid-west and include the Ordos Basin, the Sichuan Basin and the Tarim Basin. The "gold" buried at the depths of reserves is deeper than that abroad with low pressure and a low discovery rate, i.e., the reserves buried at depths of 3000-4500 m account for $46.11 \%$ of the total reserves of China. Hence, their exploration will be more difficult, generate higher costs and have a greater environmental influence. As a result, the well-head price of gas in China is equivalent to the border prices of Europe's imported gas from Russia. The influence of factors, such as geology, technology, policy and regulation, makes it difficult to effectively convert China's gas reserves into economic output, thereby preventing natural gas enterprises from generating more profits. The effective exploitation of existing natural gas under varying conditions has become a primary concern for major oil-gas enterprises. Thus, it is vital to analyze corresponding incentives, including economic, technological and regulation factors, which shape the optimizing paths in China.

Given the lack of peer-reviewed studies regarding the Chinese natural gas industry, this study aims to fill this gap by developing an optimizing approach to model gas production in China. Furthermore, this study contributes to investment planning and policy-making processes related to the gas production in China. This paper is organized as follows: A literature review is provided in Section 2. Section 3 presents the model's structure and its general description. Section 4 explains the optimal exploitation path of natural gas resources, Section 5 describes the primary results of the simulation analysis, and Section 6 provides the conclusion.

\section{Literature Review}

The issues of optimal nonrenewable resource extraction were first proposed by Hotelling [4], whose basic model predicted that the shadow price of resource stock, which is a classic measure of the scarcity of the resource, should increase at the rate of interest. Since the time of Hotelling's study, economists have expanded on his theoretical framework to allow for more realistic features. The impact of exploration activities and an extension of the resource reserves on the Hotelling framework were first suggested by Meadows et al. [5], and Solow's publication on Hotelling's model [6] boosted interest in the theory of nonrenewable resource extraction. These scholars demonstrate that exploration activities and the resource price and production path are related [7]; an increase in reserves is generally followed by an increase in production [8,9]. However, as the discovery of further reserves increases to the threshold and exploration activity declines, production also decreases. Additional analyses have been conducted, which Chermak and Patrick [10,11] classified into two primary groups: price path tests and price behavior tests. Price path tests examine if the price of a nonrenewable resource changes according to Hotelling's "r-percent rule" (i.e., whether the price increases at the rate of interest). None of the price path analyses conducted by Barnett and Morse [12], could produce evidence for the theory using actual data [13,14]. However, these tests include strong assumptions that result from simplifications in Hotelling's model. First, technology is assumed to be constant over time, and second, the relation of extraction and production costs to the resource base is not considered.

Large-scale optimization models have been successfully implemented in the copper sector $[15,16]$, as well as in other natural resource industries (e.g., Epstein et al. in the forest industry [17] or Baker and Ladson [18], and Dyer et al. [19], in the crude oil industry). Based on these systems, decision-makers are able to evaluate alternative operational policies and select those that maximize short-term and long-term profits of the business. However, for most of these models, deterministic inputs in the methodology include the net discounted value, which is predominately used by businesses.

The model utilized in this study builds on Ellis and Halvorsen [20] and Pindyck [21] regarding exploration activity. However, our model has substantially broadened the representation of the gas industry beyond that found in Pindyck's model. In particular, we attempt to address limitations that, in our opinion, made Pindyck's model a less realistic representation for the specific case of indigenous Chinese gas production.

For this reason, beginning with the economic theory of optimal resources exploitation, this paper constructs the exploitation model of resources in combination with the theories of optimal control, net 
present value and dynamic life cycle. In addition, this study developed a broadened model for the assessment of the effect of technical, cost and policy factors on the optimal exploitation of natural gas resources in China. The contribution of this study is in building the model under dynamic reserves by combining gas field benefits, gas well life cycles and gas field recovery rates into the optimal path model. The results and conclusions will be helpful for the government to formulate policies and for enterprises to make decisions.

\section{Optimal Exploitation Model of Natural Gas Resources}

\subsection{Objective Function}

The net present value of total revenue generated from natural gas within the life cycle of natural gas exploitation is presented as follows:

$$
V=\sum_{t=0}^{T-1} e^{-r t}\left[P_{t} X_{t}-C_{t}\right]
$$

where $P_{t}$ represents the market price of oil and gas resources of year $t, X_{\mathrm{t}}$ represents the exploitation volume of natural gas of year $t, e^{-r t}$ represents the discount coefficient and $C_{t}$ represents the total cost of natural gas exploitation of year $t$, including exploration cost, exploitation cost and production cost.

The objective of natural gas exploitation is to maximize the value of exploitation, namely:

$$
\max V=\sum_{t=0}^{T-1} e^{-r t}\left[P_{t} X_{t}-C_{t}\right]
$$

\subsection{Constraint Conditions}

Because natural gas is non-renewable, reserves will decrease with constant exploitation, thus satisfying:

$$
\left\{\begin{array}{l}
\left(Q_{t+1}-Q_{t}\right) \times h=-\int_{t}^{t+\tau} K_{t}(i) d_{i} \\
Q_{0}=S(0) \\
Q_{T}=S(T)
\end{array} \quad(t=0,1,2, \cdots \cdots, T-1 ; i=0,1, \cdots, \tau-1)\right.
$$

where $T$ represents the total number of years that gas resources can be exploited; $Q_{t}$ represents the remaining reserves and state variable of natural gas at the beginning of year $t ; h$ represents the recovery rate in the gas field; $\tau$ represents the life cycle of gas wells; $i$ denotes the parameter of the period(year) between $t$ and $t+\tau ; K_{t}(i)$ represents gas production volume of the $t$ batch of gas wells within the life cycle of $\tau$ years; and $\int_{t}^{t+\tau} K_{t}(i) d_{i}$ represents the total exploitation volume of the $t$ batch of gas wells within the life cycle of $\tau$ years. $\left(Q_{t+1}-Q_{t}\right) \times h=-\int_{t}^{t+\tau} K_{t}(i) d_{i}$ is a set of differential equations, modifying the transfer law from state $t$ to state $t+1$. $S(0)$ denotes the initial reserves and $S(T)$ the reserves at time $T$ at the end of the period.

In general, exploitation volume $X_{\mathrm{t}}$ is realized through the production volume of different batches of gas wells at time $t$. Every batch of gas wells experiences an output rising period, a stable period and an output reduction period within a life cycle of $\tau$ years; however, the output functions of each batch of gas wells within the life cycle are not necessarily consistent (Figure 1). Let $K_{t}(i)$ denote the exploitation function of the $t$ batch of gas wells in period $i$ within the life cycle of $\tau$ years. The following four inverted "U-shaped" curves demonstrate the schematic diagrams of converting the capacity of different batches of gas wells to output. The production curve is inverted and declines sharply because each well has a short life cycle. Hence, the incremental curve is the accumulative production for the gas fields. In consideration of the functionality of the graph, the schematic diagrams of gas well exhaustion for other years are not plotted. 


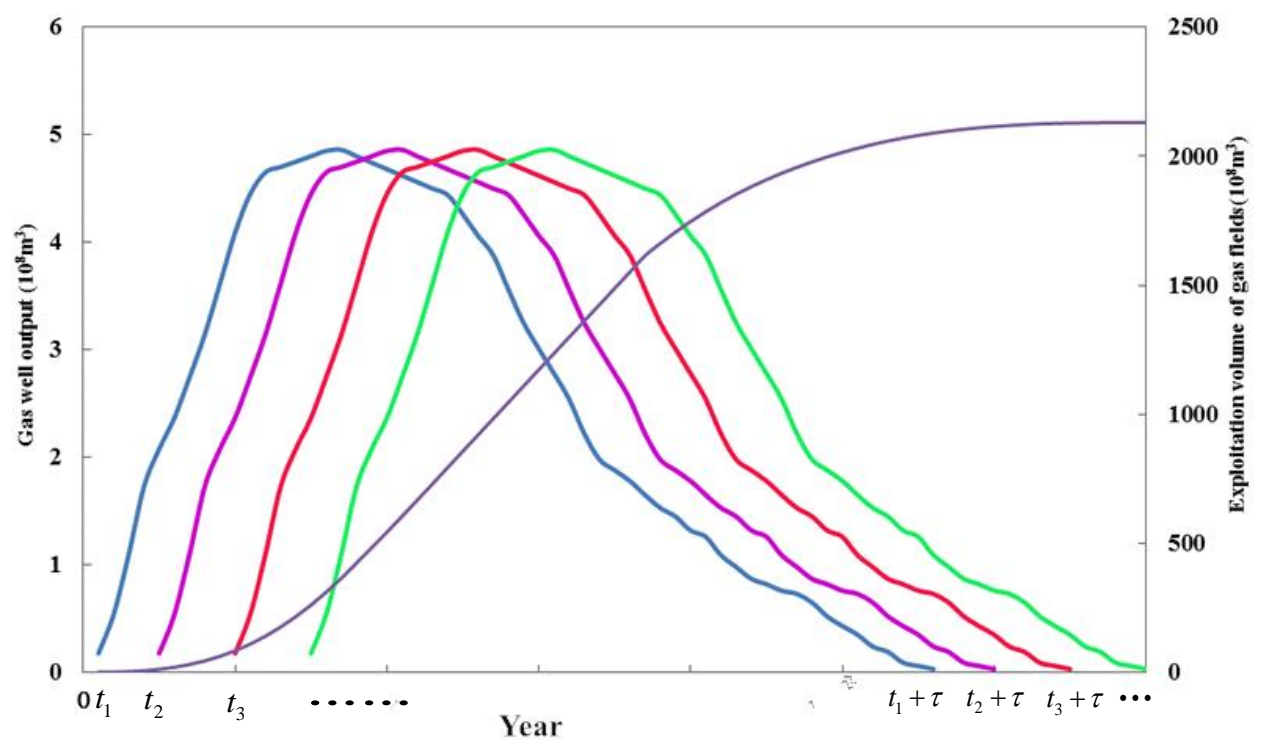

Figure 1. Velocity of converting the capacity of different batches of gas wells to output.

Assuming the life cycle of gas wells is $\tau$, the capacity $\int_{t}^{t+\tau} K_{t}(i) d_{i}$ of the $t$ batch of gas wells utilized in year $t$ will be converted to output between year $t$ and year $t+\tau$. For gas fields, the natural gas exploitation volume of year $t$ is the sum total of the natural gas produced by the $t+\tau$ batch and $t$ batch of gas wells at time $t$. The conversion of the capacity of different batches of gas wells satisfies the following equation:

$$
\left\{\begin{array}{l}
\mathrm{X}(\mathrm{t})=\int_{0}^{1} K_{t}(x) d_{x}+\int_{1}^{2} K_{t-1}(x) d_{x}+\cdots+\int_{i-1}^{i} K_{t-i+1}(x) d_{x}+\cdots+\int_{t-\tau}^{t-\tau+1} K_{t-1}(x) d_{i} \\
\int_{i-1}^{i} K_{t}(x) d_{x}=f(t, i)
\end{array}\right.
$$

where $i \in[0, \tau], t \in[0, T]$.

We denote $K_{t}(i)$ as the exploitation function of the $t$ batch of gas wells at time $i$ within the life cycle of $\tau$ years;

$\int_{i-1}^{i} K_{t}(x) d_{x}$ denotes the exploitation volume of the $t$ batch of gas wells at time $i$ within the life cycle of $\tau$ years.

\subsection{Optimal Conditions}

The above objective function and constraint conditions constitute the inter-temporal optimized model of natural gas optimal exploitation, namely the optimal exploitation model of dynamic natural gas resources. The model of the reasonable natural gas exploitation scale is transformed into an unconstrained Lagrange extremum problem with $T-1$ constraint conditions, as demonstrated below:

$$
\begin{aligned}
L & =\sum_{t=0}^{T-1} e^{-r t}\left[P_{t} X_{t}-C\right]+\sum_{t=0}^{T-1}\left\{e^{-r(t+1)} \lambda_{t+1}\left[-\int_{t}^{t+\tau} K_{t}(x) d_{x}+\left(Q_{t+1}-Q_{t}\right) \times h\right]\right\} \\
& =\sum_{t=0}^{T-1} e^{-r t}\left\{\left[P_{t} X_{t}-C\right]+e^{-r} \lambda_{t+1}\left[-\sum_{i=1}^{\tau} f(t, i)+\left(Q_{t+1}-Q_{t}\right) \times \mathrm{h}\right]\right\}
\end{aligned}
$$

To calculate the extremum conditions for Equation (5), the Hamilton function is introduced; let:

$$
\left\{\begin{array}{l}
H=H\left(X_{t}, Q, \lambda_{t+1}, t\right)=P_{t} X_{t}-e^{-r} \lambda_{t+1} F(t) \\
F(t)=\sum_{i=1}^{\tau} f(t, i)
\end{array}\right.
$$


Substituting Equation (5) into Equation (6) produces the following:

$$
L=\sum_{t=0}^{T-1}\left[H+e^{-r} \lambda_{t+1}\left(Q_{t+1}-Q_{t}\right) \times h\right] e^{-r t}
$$

Conditions necessary to take the extreme value in Equation (7):

$$
\left\{\begin{array}{l}
\frac{\partial H}{\partial X_{t}}=P_{t}-M C-e^{-r} \lambda_{t+1}=0 \\
\frac{\partial H}{\partial Q_{t}}=e^{-r(t+1)} \lambda_{t+1}-e^{-r t} \lambda_{t}=0 \\
\frac{\partial H}{\partial \lambda_{t+1}}=-\sum_{i=1}^{\tau} f(t, i)+\left(Q_{t+1}-Q_{t}\right) \times h=0
\end{array} \quad(t=0,1,2, \cdots \cdots, T-1)\right.
$$

$M C$ represents the marginal cost. The optimal conditions for Equation (5) can be derived from Equations (6)-(8):

$$
\left\{\begin{array}{l}
P_{t}-M C-e^{-r} \lambda_{t+1}=0 \\
e^{-r} \lambda_{t+1}=\lambda_{t} \\
\left(Q_{t+1}-Q_{t}\right) \times h=-F(t)
\end{array} \quad(t=0,1,2, \cdots \cdots, T-1)\right.
$$

Substitute Equations (8) and (9) into Equation (7); we calculate the following:

$$
P_{t}-M C-e^{r t} \lambda_{0}=0(t=0,1,2, \cdots \cdots, T-1)
$$

It can be determined from the above equation sets that $\lambda_{0} *$ and optimal path $X_{t}^{*}$ can be obtained as long as the functional relations between $M C, Q_{t}, X_{t}, h$ and $K_{t}(i)$ in different time periods are available.

\section{Optimal Exploitation Path of Natural Gas Resources}

\subsection{Parameters Setting}

Based on the above model analysis, this section selects a gas field in the Ordos Basin as the research target and simulates scenarios to solve for the optimal exploitation scale. The selected gas field is typical, features "three lows" (low porosity, low permeability and low pressure) and represents an onshore gas field in China. This gas field has been exploited for more than ten years and is currently in the output rising period. The analysis of the parameters involved in this study is described in the following text.

\subsubsection{Gas Field Exhausting Time $T$}

Because the optimal exhausting rate (an analytical solution with implicit $T$ ) involves the setting of time $T$, the optimal exploitation scale can be solved according to the inter-temporal optimized model of natural gas exploitation scale when $T$ is set. In addition, a gas field has a life cycle. The gas field in the Ordos Basin has a short production period, so its life cycle is divided into three periods (i.e., output rising period, stable period and output reduction period) with $t_{k}, t_{s}-t_{k}$ and $T-t_{s}$ denoting the corresponding years for each period. In this section, the life cycle of this gas field is denoted as $T=40$ years, of which $t_{k}=12$ years are in the output rising period, $t_{s}-t_{k}=13$ years are in the stable period and $T-t_{s}=15$ years are in the output reduction period.

\subsubsection{Marginal Exploitation Cost of Natural Gas MC}

We consider the fact that estimation of the marginal cost represents the optimization problem of the gas producer. From a modeling perspective, we would prefer the marginal cost to depend on the actual sequence of extraction. This consideration in our formulation is particularly useful for modeling underground mining operations in which production costs tend to increase as extraction progresses. This assumption allows us to formulate the decision-maker's optimization problem 
using linear programming methods. The exploitation cost of natural gas $C$ refers to the total costs incurred during the development of natural gas, particularly the exploration cost, development cost and production cost. For simplicity, this study assumes that the marginal costs of exploration and development are constant.

In regards to the cost of production, this study divides the exhausting period $T$ of the gas field into the output rising period, the stable period and the output reduction period according to its life cycle. Combining the above hypotheses, the marginal cost of production within period $T$ is determined as demonstrated below:

$$
\begin{cases}M C P(t)=a t+b & \left(1 \leqslant t \leqslant t_{k}\right) \\ M C P(t)=c & \left(t_{k} \leqslant t \leqslant t_{s}\right) \\ M C P(t)=d t+e & \left(t_{s} \leqslant t \leqslant T\right)\end{cases}
$$

where $M C P(t)$ represents the marginal cost of production at time $t$ and $a, b, c, d, e$ are the coefficients of the marginal cost of production $M C P(t)$ in different time periods.

Marginal costs are determined according to the life cycle. The marginal cost of exploration is $M C E=0.05 \mathrm{CNY} / \mathrm{m}^{3}$; the marginal cost of development is $M C D=0.05 \mathrm{CNY} / \mathrm{m}^{3}$; and the coefficients of the marginal cost of production $M C P(t)$ are $a=0.02, b=0.082, c=0.056, d=0.004, e=-0.04$.

\subsubsection{Discount Rate $r$}

In addition to a risk-free discount rate, the discount rate should consider the rate of risk return; specifically, it should reflect the time value of money and risks associated with the project. Therefore, consideration of capital's time value and the discount of infrastructure is necessary. There are reliable methods of determining the discount rate. Many scholars have determined the discount rate to be between 0.05 and 0.2 [22,23]. In alignment with the current situation and the future development trend of natural gas in China, national long-term loans and treasury bond rate information in related references, the discount rate is denoted as 0.07 .

\subsubsection{Recovery Rate $h$}

Gas well exploration, exploitation and production processes generally involve converting reserves to capacity and then capacity to output. However, recoverable reserves in gas fields will not necessarily be completely converted to capacity, nor will capacity always be converted to output. Recovery rate refers to the ratio of oil and gas volume extracted from reservoirs with reserves within a certain economic limit and through the use of modern technical skills. The oil and gas recovery rate varies from field to field in China. Taking into account the geological features and natural gas prices in this field, the recovery rate is denoted as 0.6 .

\subsubsection{Exhausting Rate of Gas Wells $\tau$}

The life cycle of different batches of gas wells in the gas field analyzed for this study is: $\tau=5$ years, where the velocities of converting capacity to reserves in each year are, respectively, $0.1,0.2,0.3,0.3$ and 0.1 .

\subsubsection{Reserves $S$}

The proven recoverable reserves in this gas field is $S(0)=3000 \times 10^{8} \mathrm{~m}^{3}$. For simplicity, the closing natural gas reserves are denoted as $S(T)=0$.

\subsection{Optimal Path}

The optimal exploitation scale and path of remaining reserves for the gas field under study is calculated by combining the above parameters. As can be noted in Figure 2, for a life cycle of 40 years, the gas field shows an obvious growth period, a stable period and an output reduction period, with the exploitation volume increasing rapidly in the growth period, slowing down in the stable period 
and decreasing significantly in the output reduction period. Remaining reserves present a reversed $\mathrm{S}$-shaped curve in the life cycle. It can be demonstrated from comparative analysis of the calculation results of the model with the practical data from this gas field that the output error in Period 3 is $26.7 \%$, and the gas produced in a period of 12 years (Periods 1-12) has a relatively lower average error of $9.1 \%$, indicating that the simulation results of the model are reliable (shown in Table 1).

Table 1. Analysis of output error in a gas field model.

\begin{tabular}{ccccccccccccc}
\hline Period (Years) & $\mathbf{1}$ & $\mathbf{2}$ & $\mathbf{3}$ & $\mathbf{4}$ & $\mathbf{5}$ & $\mathbf{6}$ & $\mathbf{7}$ & $\mathbf{8}$ & $\mathbf{9}$ & $\mathbf{1 0}$ & $\mathbf{1 1}$ & $\mathbf{1 2}$ \\
\hline Statistical data $\left(10^{8} \mathrm{~m}^{3}\right)$ & 1.2 & 3.8 & 7.7 & 12.1 & 14.6 & 16.6 & 19.2 & 22 & 25.3 & 28.6 & 32.2 & 36.1 \\
Practical data $\left(10^{8} \mathrm{~m}^{3}\right)$ & 1.4 & 4 & 10.5 & 14.3 & 13.8 & 14.2 & 17.8 & 22 & 24 & 28 & 31 & 34 \\
Error $(\%)$ & -14.3 & -5 & -26.7 & -15.4 & 5.8 & 16.9 & 7.9 & 0 & 5.4 & 2.1 & 3.9 & 6.2 \\
\hline
\end{tabular}

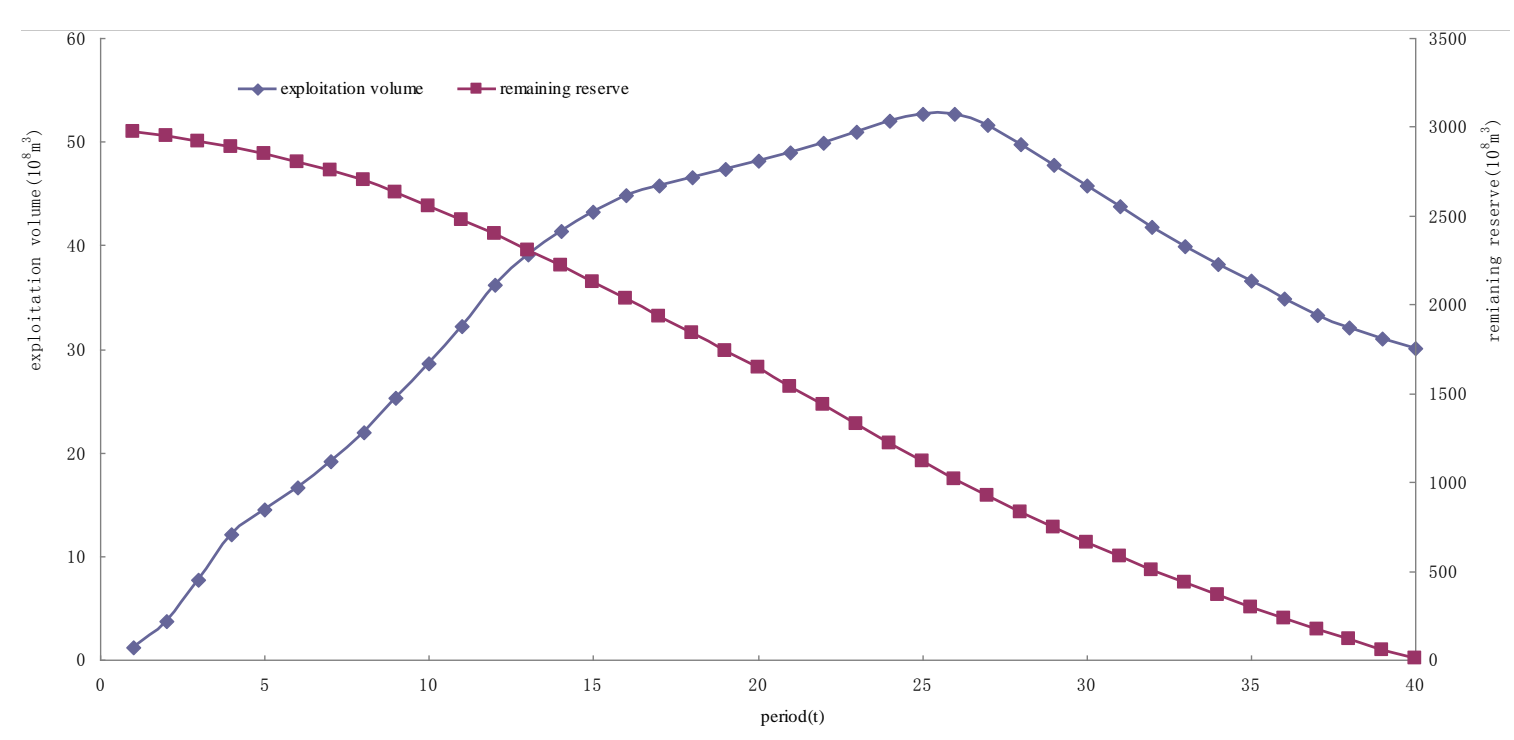

Figure 2. Exploitation scale and remaining reserves in a gas field.

\section{Result Analysis and Discussion}

Factors, such as the discount rate, recovery rate and price, will inevitably affect the optimal path of natural gas exploitation. This study designates price as the exogenous variable and the discount rate, recovery rate and the speed of converting capacity to output as the endogenous variables. Combining these variables with the above model, this section analyzes the impact of these endogenous variables on the optimal exploitation model of natural gas resources.

\subsection{Increase in Discount Rate Accelerating Natural Gas Exploitation}

The discount rate reflecting time value is closely related to the bank interest rate included in national macro-regulations. According to the Hotelling rule, the interest rate exerts an important influence on the decision of natural gas exploitation. Here, the natural gas exploitation volume and remaining reserves are simulated when the discount rates are $0.05,0.07$ and 0.12 .

When utilizing different discount rates, the natural gas exploitation curve is generally inconsistent with the remaining reserves curve. To clarify, the exploitation volume can also reflect the output rising period, the stable period and the output reduction period of natural gas, and the remaining reserves curve still presents a reversed S-shaped curve (shown in Figure 3). In the output rising period and stable period, the exploitation volume with a discount rate of 0.12 is obviously higher than one with a discount rate of 0.07 . At the end of the stable period, the exploitation volume with a discount rate of 0.05 is similar to one with a discount rate of 0.07 . In the output reduction period, the exploitation volume with a discount rate of 0.12 drops fastest, followed by one with a discount 
rate of 0.07 . The three curves intersect at the 29th point of time. In the output rising period and stable period of natural gas exploitation, the exploitation volume will rise with an increase in the discount rate, and investors are more willing to fund natural gas exploitation; while in the output reduction period, the greater the discount rate, the more significant the output reduction is, and investors are less willing to fund natural gas exploitation (shown in Figure 4).

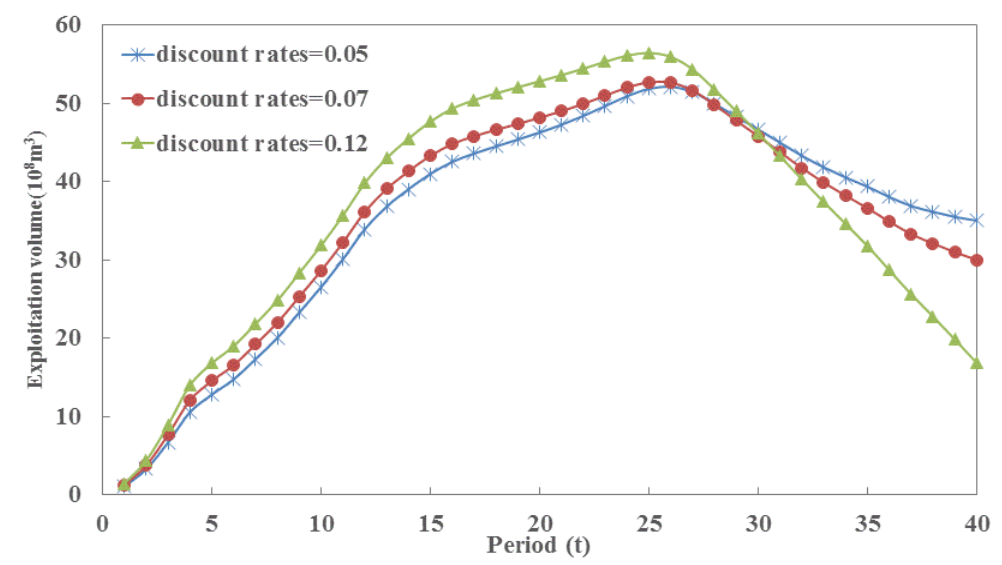

Figure 3. Exploitation volume with different discount rates.

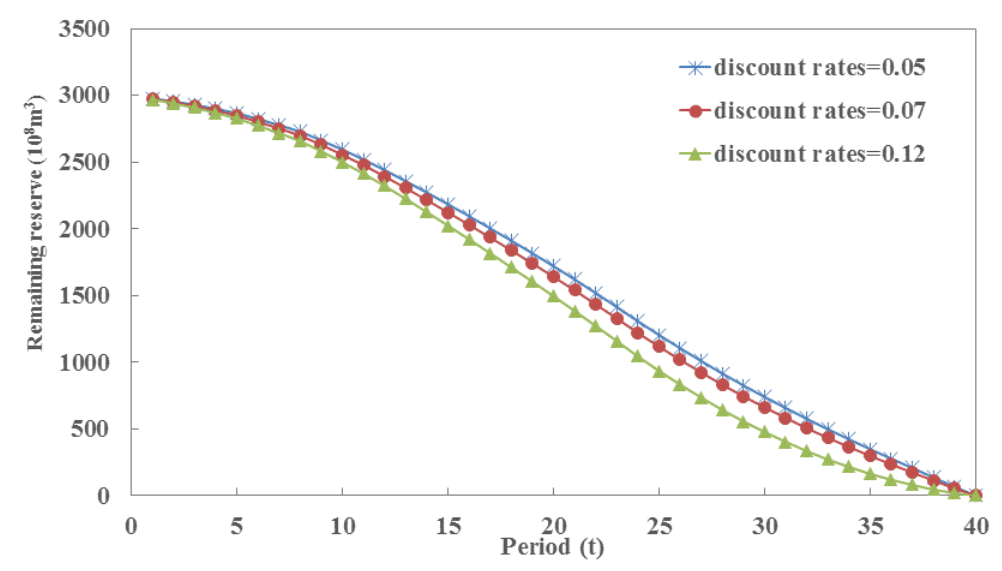

Figure 4. Remaining reserves with different discount rates.

\subsection{Increase in Recovery Rate Increases Economically-Recoverable Reserves of Natural Gas}

The recovery rate generally affects the recoverable reserves of natural gas, thus affecting the exploitation volume of natural gas in different time periods (shown in Figure 5). The gas field recovery rate in China varies from field to field. Even in different areas of the same gas field, recovery rates are not identical. Exploitation rates of natural gas in the Sichuan Basin, Ordos Basin, Bohai Bay Basin, Songliao Basin, Junggar Basin, Tarim Basin and Qaidam Basin are 40.3\%-81.77\%, 58.33\%-70.07\%, $57 \%-68 \%, 52 \%-63.5 \%, 51.02 \%-84.48 \%, 54 \%-74.08 \%$ and $53.83 \%-75.25 \%$, respectively. Thus, the recovery rates selected in this paper are $0.4,0.5,0.6,0.7$ and 0.8 . Natural gas with a recovery rate of 0.7 has the same exploitation volume as that with a recovery rate of 0.8 , and natural gas with a recovery rate of 0.7 has a higher exploitation volume than that with a recovery rate of 0.6 . Through calculation, it is determined that in the range of $0.4-0.7$, the recovery rate will increase by $10 \%$, with an average incremental exploitation volume of 3.799 billion cubic meters in yield in the rising period, 7.895 billion cubic meters in the stable period and 15.693 billion cubic meters in the yield reduction period (shown in Figure 6). This indicates that within a certain range, exploitation volume increases as the recovery 
rate of the gas field increases. When the recovery rate further increases, the exploitation volume of natural gas remains the same.

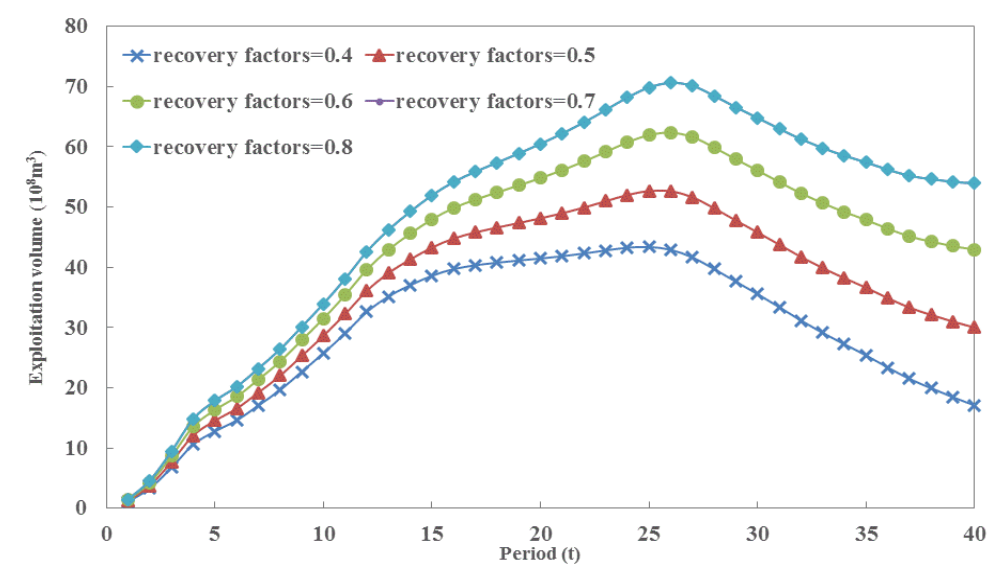

Figure 5. Exploitation volume with different recovery rates.

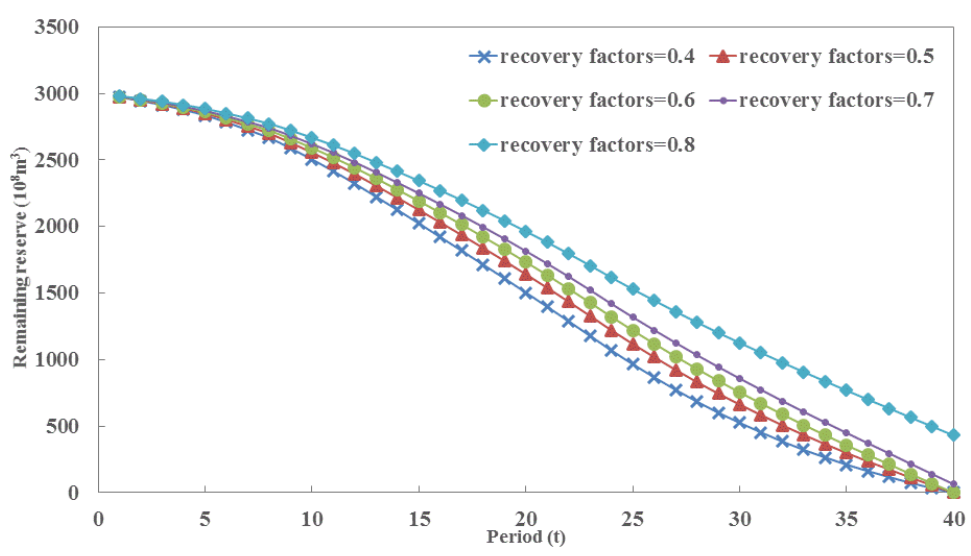

Figure 6. Remaining reserves with different recovery rates.

\subsection{Exhausting Rate of Gas Wells Extending the Distribution of Natural Gas in Fields}

As stated above, the velocity of converting gas well capacity to output will affect the exploitation scale of natural gas by altering the distribution of every batch of gas wells within the life cycle of the gas field (shown in Figure 7), but annual capacity, or specifically the dynamic reserves, will not change; which explains why the remaining reserves curves of the gas field are entirely consistent with each other (shown in Figure 8). When the life cycle of gas wells is set at three years, the velocities of converting capacity to output are $0.3,0.4$ and 0.3 , and in the case of seven years, the corresponding velocities are $0.1,0.1,0.2,0.2,0.2,0.1$ and 0.1 . Overall, the longer it takes for the gas well capacity to be converted to output, or rather the longer the life cycle of gas wells, the further the gas exploitation curve will move to the right. In the output rising period, gas wells with a life cycle of three years have a significant higher exploitation volume than those with a life cycle of five years or seven years. In the stable period, the three exploitation curves essentially overlap each other. In the output reduction period, gas wells with a life cycle of seven years have a significantly higher exploitation volume than those with a life cycle of three years or five years. To clarify, in the output rising period, the faster the gas well capacity is converted to output, the greater the exploitation volume in the gas field, but during the output reduction period, the longer it takes for the gas well capacity to be converted to output, the greater the exploitation volume. 


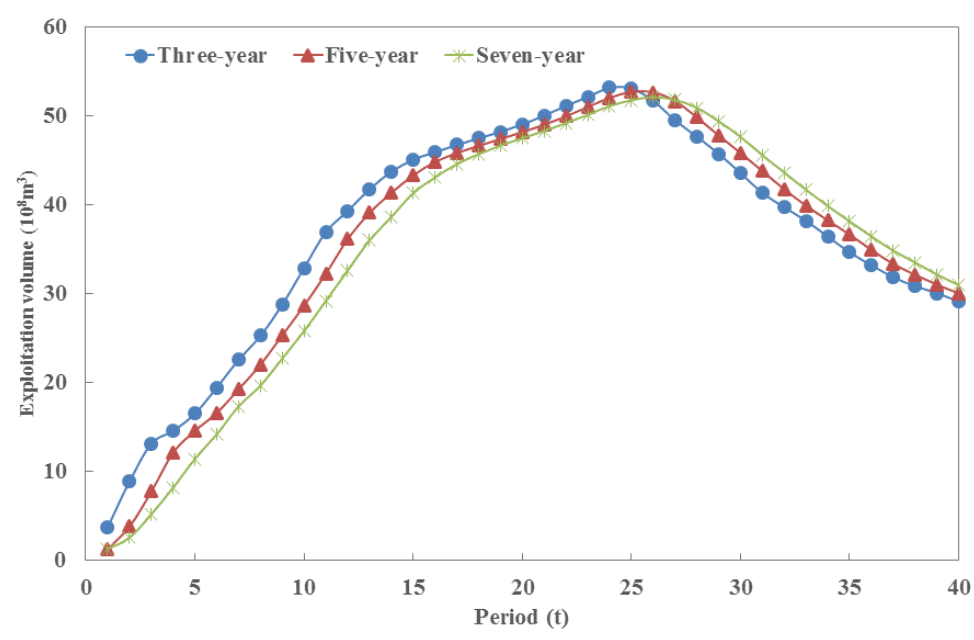

Figure 7. Exploitation volume with different exhausting rates of gas wells.

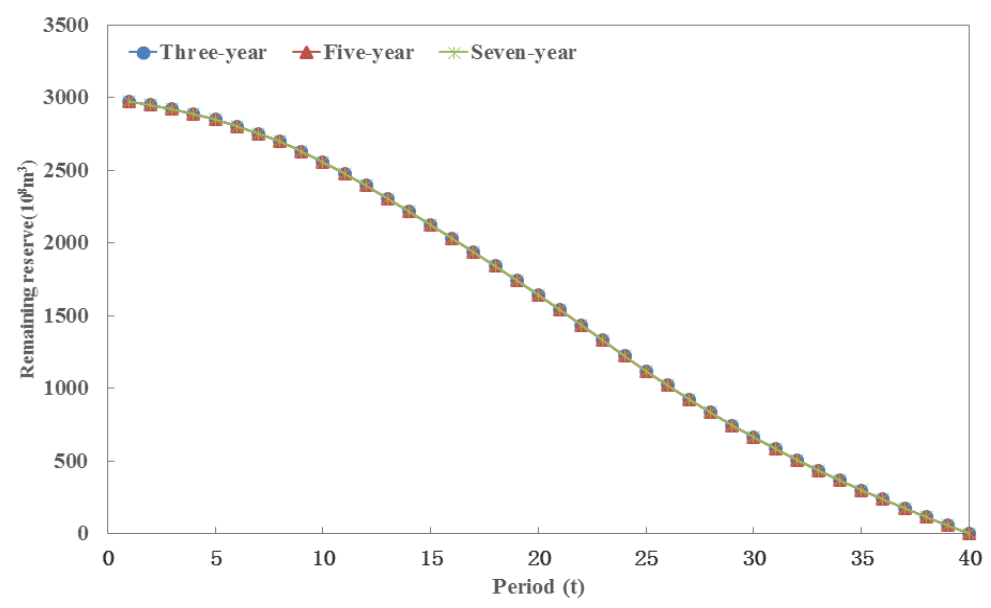

Figure 8. Remaining reserves with different exhausting rates.

\subsection{Price Increase Leads to Increased Economically-Recoverable Reserves in Gas Fields}

In China, the price of natural gas is regulated by the state, which utilizes a cost-plus pricing mechanism. As a price-taker, enterprises can make corresponding adjustments to allow for price fluctuations. It is quite necessary, therefore, to analyze how price affects the rate of natural gas exploitation.

The initial price of natural gas is determined by the regulation authority in China and is used as an input and an exogenous variable in this study. On the basis of the influence of prices fluctuating in the range of $10 \%$, the path of natural gas exploitation is analyzed. As shown in the Figure 9 , when the price increases by $10 \%$, exploitation volume increases in the output rising period and stable period, but decreases in the output reduction period. Otherwise, exploitation volume decreases in the output rising period and the stable period, but increases in the output reduction period. Three curves intersect at the end of the stable period and at the beginning of the output reduction period. Corresponding to the exploitation volume, the remaining reserves decrease rapidly with a higher price in the stable and reduction period (see Figure 10). Due to price increases, the break-even point moves upwards, because the revenue of natural gas exploiting enterprises increases, thus increasing the economic recoverable reserves and then increasing the exploitation volume of natural gas enterprises. 


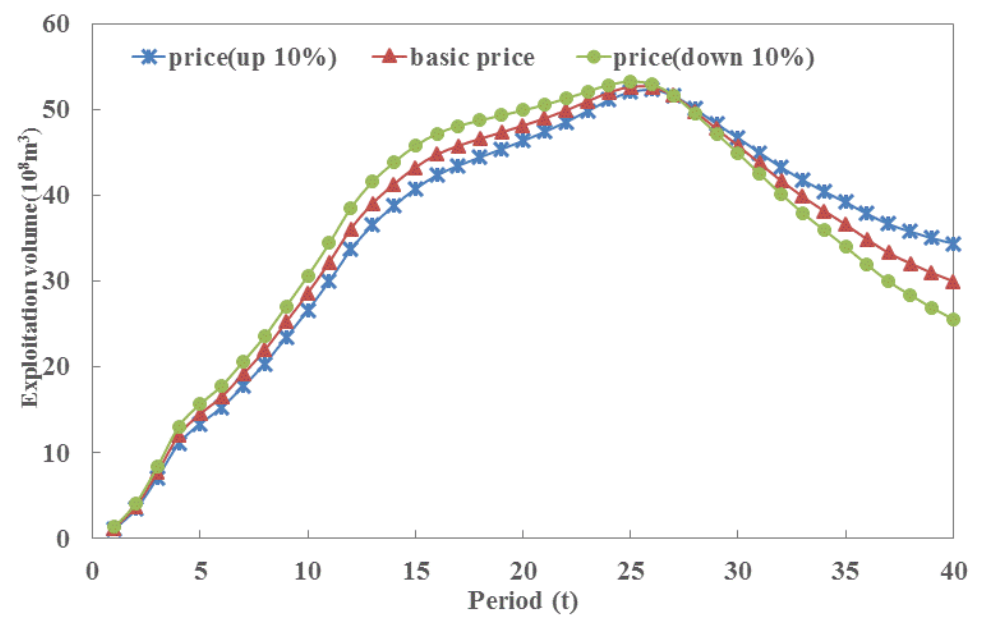

Figure 9. Exploitation volume with different prices.

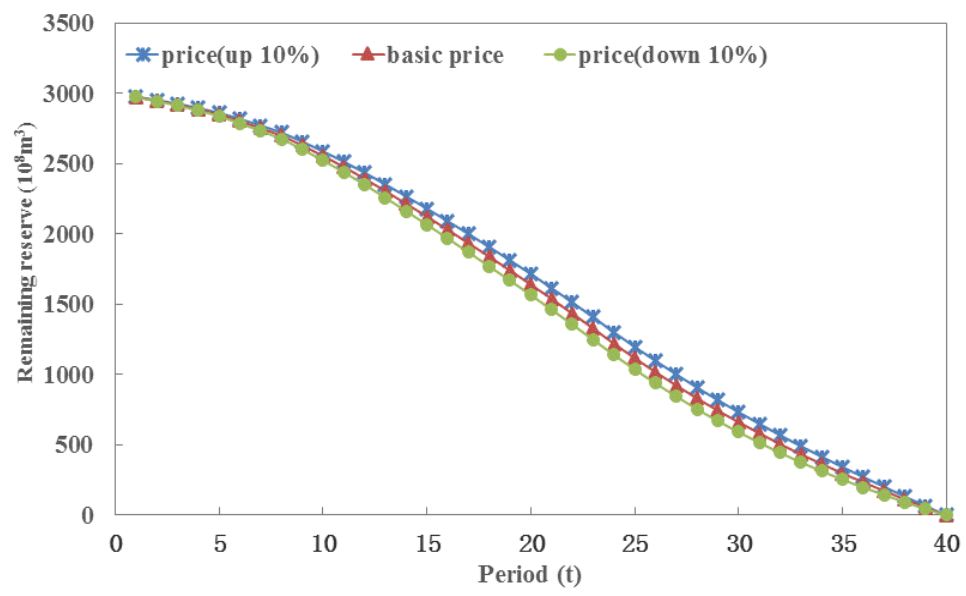

Figure 10. Remaining reserves with different prices.

\section{Conclusions and Remarks}

Based on current large-scale natural gas exploitation, combining real data with the optimal control theory and using the net present value method, this study builds the optimal exploitation model of natural gas resources to analyze the optimal exploitation path of the gas field within its life cycle using the Ordos Basin as the example. In addition, this study conducts a sensitivity analysis of the factors affecting the path of natural gas exploitation. The following conclusions are drawn from the calculations and analysis.

Upon comparison, the average error between the calculation results of the model and actual data regarding reserves is only $9.1 \%$, which demonstrates that the exploitation path is relatively reasonable at present and suggests a certain degree of practical operability of this model. The gas field used in this analysis is now in the output rising period and will soon enter the stable period. Appropriate adjustments should be made to the optimized model if its exploitation conditions improve.

The discount rate affects the exhausting rate of gas fields. A higher discount rate results in quicker exploitation of natural gas and, therefore, faster exhaustion of gas fields. In addition, investors' decisions regarding natural gas exploitation will be affected by the discount rate; as the discount rate increases, enterprises will invest greater amounts. Thus, the exploitation volume of natural gas shows a significant increase in the output rising period and stable period, increasing the speed of exhaustion for gas fields in the output reduction period. 
A larger recovery rate results in an increased exploitation volume of gas fields in each time period and results in greater potential of increasing output in gas fields. The recoverable reserves of gas fields and output-increasing potential will increase as a result of more scientific research data and technological advancements. Meanwhile, an increase in gas prices may increase the economic recoverable reserves, thus resulting in an increase in the recovery rate of gas fields.

The exhaustion cycle of gas wells affects the velocity of the converting capacity to output and the distribution of the natural gas in the life cycle of gas fields. The faster the conversion, the more output increases in the output rising period and the faster output decreases in the output reduction period.

Price affects the economically-recoverable reserves of gas fields. When prices rise, the economically-recoverable reserves increase, as does the exploitation volume. Because China's natural gas was underpriced for a long period of time due to government control, natural gas prices were expected to increase as a result of pricing reform [24]. It may be reasonable to deduct that natural gas producers' benefit the most from rising prices.

To our knowledge, this is one of the few papers that explicitly analyzes natural gas resources exploitation utilizing an optimizing model for a regulated market. The potential practical value will make it possible to theoretically analyze and calculate the model of optimal resource exploitation rates under uncertain scenarios, which is of great theoretical value and practical significance to the selection of the resource exploitation path.

There are limitations to this analysis. For example, we analyze the effects of increased gas prices of a stated-owned gas producer and ignore the optimal domestic gas pricing level. In addition, we do not consider the constraints of the demand structure in downstream sectors, which shape the behavior of upstream producers. To enhance future natural gas market research, the multi-agent non-linear programming model should be developed to account for the interaction among producers, sellers and end-users.

Acknowledgments: The authors gratefully acknowledge the financial support provided by the Ministry of Education of China under the name of its Philosophy and Social Science Major Issue Research Project "Natural gas production and transportation peak signal extraction and optimization strategies" (No. 11YJC630211).

Author Contributions: Jianzhong Xiao contributed to the design of the article. Xiaolin Wang designed the model and wrote the paper. Ran Wang collected and analyzed the data.

Conflicts of Interest: The authors declare no conflict of interest.

\section{Nomenclature}

$\begin{array}{ll}\text { Abbreviation } & \text { National Oil Company } \\ \text { NOC } & \text { China Petroleum and Chemical Corporation } \\ \text { Sinopec } & \text { National Development and Reform Commission } \\ \text { NDRC } & \text { cubic meter } \\ \mathrm{m}^{3} & \\ \text { Model Symbol Definitions } & \text { market price of natural gas }\left(\mathrm{CNY} / \mathrm{m}^{3}\right) \\ P & \text { total cost of natural gas exploitation }\left(\mathrm{CNY} / \mathrm{m}^{3}\right) \\ C & \text { time series } \\ t & \text { gas field exhaustion time }(\text { year }) \\ T & \text { discount rate of capital }(\%) \\ r & \text { recover rate of the gas field }(\%) \\ h & \text { exhausting rate of gas wells }(\%) \\ \tau & \text { proven recoverable reserves }\left(\mathrm{m}^{3}\right) \\ S & \end{array}$




\section{References}

1. Dong, X.; Jie, G.; Mikael, H.; Guanglin, P. Sustainability Assessment of the Natural Gas Industry in China-Using Principal Component Analysis. Sustainability 2015, 7, 6102-6118. [CrossRef]

2. Yan, X.-C. Energy structure optimization and strategic position and role of natural gas in China. Int. Petr. Econ. 2010, 3, 62-67.

3. Dai, J.; Wu, W.; Fang, C.; Liu, D. Exploration and development of large gas fields in China since 2000. Nat. Gas Ind. B 2015, 2, 1-8. [CrossRef]

4. Hotelling, H. The economics of exhaustible resources. J. Political Econ. 1931, 39, 137-175. [CrossRef]

5. Meadows, D.H.; Goldsmith, E.I.; Meadow, P. The Limits to Growth; Earth Island Limited: London, UK, 1972; Volume 381.

6. Solow, R.M. The economics of resources or the resources of economics. In Classic Papers in Natural Resource Economics; Palgrave Macmillan: Basingstock, UK, 1974; pp. 257-276.

7. Stiglitz, J.E. Monopoly and the rate of extraction of exhaustible resources. Am. Econ. Rev. 1976, 66, 655-661.

8. Halvorsen, R.; Smith, T.R. On measuring natural resource scarcity. J. Political Econ. 1984, 92, 954-964. [CrossRef]

9. Halvorsen, R.; Smith, T.R. A test of the theory of exhaustible resources. Q. J. Econ. 1991, 106, $123-140$. [CrossRef]

10. Chermak, J.M.; Patrick, R.H. Comparing tests of the theory of exhaustible resources. Resour. Energy Econ. 2002, 24, 301-325. [CrossRef]

11. Chermak, J.M.; Patrick, R.H. A microeconometric test of the theory of exhaustible resources. J. Environ. Econ. Manag. 2001, 42, 82-103. [CrossRef]

12. Barnett, H.J.; Morse, C. The economics of natural resource availability. In Scarcity and Growth; Routledge: Abingdon, UK, 2013; Volume 3.

13. Slade, M.E. Trends in natural-resource commodity prices: An analysis of the time domain. J. Environ. Econ. Manag. 1982, 9, 122-137. [CrossRef]

14. Slade, M.E.; Thille, H. Hotelling confronts CAPM: A test of the theory of exhaustible resources. Can. J. Econ. 1997, 30, 685-708. [CrossRef]

15. Mondschein, S.; Schilkrut, A. Optimal investment policies for pollution control in the copper industry. Interfaces 1997, 27, 69-87. [CrossRef]

16. Caldentey, R.; Mondschein, S. Policy model for pollution control in the copper industry, including a model for the sulfuric acid market. Oper. Res. 2003, 51, 1-16. [CrossRef]

17. Epstein, R.; Morales, R.; Seron, J.; Weintraub, A. Use of OR systems in the Chilean forest industries. Interfaces 1999, 43, 64-79. [CrossRef]

18. Baker, T.E.; Ladson, L.S. Successive linear programming at exxon. Manag. Sci. 1985, 31, 264-274. [CrossRef]

19. Dyer, J.S.; Lund, R.L.; Larsen, J.B.; Leone, R.P. A decision support system for prioritizing oil and gas exploration activities. Oper. Res. 1990, 38, 386-396. [CrossRef]

20. Ellis, G.M.; Halvorsen, R. Estimation of market power in a nonrenewable resource industry. J. Political Econ. 2002, 110, 883-899. [CrossRef]

21. Pindyck, R.S. The optimal exploration and production of nonrenewable resources. J. Political Econ. 1978, 86, 841-861. [CrossRef]

22. Hu, M.-C.; Hobbs, B.F. Analysis of multi-pollutant policies for the U.S. power sector under technology and policy uncertainty using MARKAL. Energy 2010, 35, 5430-5442. [CrossRef]

23. Schäfer, A.; Jacoby, H.D. Vehicle technology under $\mathrm{CO}_{2}$ constraint: A general equilibrium analysis. Energy Policy 2006, 34, 975-985. [CrossRef]

24. Paltsev, S.; Danwei, Z. Natural gas pricing reform in China: Getting closer to a market system? Energy Policy 2015, 86, 43-56. [CrossRef]

(C) 2016 by the authors; licensee MDPI, Basel, Switzerland. This article is an open access article distributed under the terms and conditions of the Creative Commons Attribution (CC-BY) license (http://creativecommons.org/licenses/by/4.0/). 